\title{
Effect of suction on the posterior segment after LASIK using Femtosecond Laser vs Microkeratome
}

\author{
H.M.El- Feky, A.M.Saeed and A.S.Abdel Aziz \\ Ophthalmology Dept., Faculty of Medicine, Benha Univ., Benha, Egypt \\ E-mail: Ahmed_said90@ hotmail.com
}

\begin{abstract}
Background: Creating a successful corneal flap is the first critical step during LASIK surgery. Two techniques are used to produce corneal flaps during LASIK surgery: a microkeratome or a femtosecond laser. Femtosecond laser has a significant impact on refractive surgery by enabling non-mechanical creation of corneal flaps during laser in situ keratomileusis (LASIK). During LASIK flap creation, intraocular pressure (IOP) increases to levels exceeding $65 \mathrm{~mm} \mathrm{Hg}$. Femtosecond laser flap creation exerts less extreme IOP fluctuations but requires more procedural time than when a microkeratome is used. This study was conducted upon 60 eyes of 38 patients to evaluate the effect of applied suction during LASIK procedures on the posterior segment of myopic eyes, whether the flap was created by Microkeratome or Femtosecond laser. The study subjects were equally divided into 2 groups: group F (30 eyes of 20 patients) underwent femtosecond laser-assisted LASIK surgery and group M (30 eyes of 18 patients) underwent microkeratome-assisted LASIK surgery using Moria M2 for the treatment of myopia. It was found that the central macular thickness and RNFL thickness were not changed significantly in both groups when measured 1 week after surgery. Regarding the incidence of PVD, there was a higher incidence in group F, it was detected in 8 eyes (26.7\%) compared to group M, it was detected in 1 eye $(3.3 \%)$. Conclusion: Slight localized changes of macular thickness and reduction of the RNFL thickness were caused by LASIK using the two major forms of flap creation, namely a microkeratome or a femtosecond laser. Regarding the incidence of PVD, it was found that femtosecond laser-assisted LASIK using Visumax femtosecond laser had a higher incidence than that after microkeratome-assisted LASIK with the Moria M2. So the surgery of LASIK is safe and efficient, but surgeons should choose effective and safe suction mode, shorten the suction time and exclude potential retinopathy and pre-existing glaucoma before surgery to improve the safety and efficacy of LASIK.
\end{abstract}

Keywords: Femtosecond Laser, LASIK, Microkeratome.

\section{Introduction}

Laser in situ keratomileusis (LASIK) is the commonest ophthalmologic surgical procedure used to correct refractive error. Due to decreased time of recovery and post-procedure complications, this surgery quickly became popular. LASIK is among the most studied surgical procedures to have gone through FDA inspection since its introduction in clinical practice. [1]

Creating a successful corneal flap is the first critical procedure during LASIK surgery. Two techniques are used to produce corneal flaps during LASIK surgery: a microkeratome or a femtosecond laser.

Femtosecond laser has a significant influence on refractive surgery by enabling non-mechanical creation of corneal flaps during laser in situ keratomileusis (LASIK). The femtosecond laser offers advantages over microkeratomes. These include increased precision, a reduced incidence of flap complications, and the ability to cut thinner flaps without the risk of button-hole formation. [2]

Intraocular pressure (IOP) increases to high levels exceeding $65 \mathrm{~mm} \mathrm{Hg}$ during LASIK flap creation. Femtosecond laser flap creation exerts less IOP fluctuations but requires more time than when using a microkeratome. The sudden spike in IOP, which can damage the eye, has been noted during LASIK. [3]

One hypothesis is that the axial length of the eye changes during suction ring application (lengthening or shortening), resulting in vitreoretinal traction at the vulnerable macula and vitreous base, which may result in various posterior segment effects ranging from PVD to rhegmatogenous RD. The incidence of posterior segment complications should theoretically decrease with the recent introduction of the femtosecond laser in refractive surgery because of the lower vacuum required during the suction phase, which should result in less vitreoretinal traction. [4]

\section{Aim of the work}

To assess and compare the posterior segment changes as incidence of PVD, macular and peripapillary retinal nerve fibre layer thickness changes after femtosecond laser vs microkeratome assisted LASIK.

\section{Patients and methods}

This prospective, non-randomized comparative clinical trial was conducted upon 60 eyes of 38 patients. The study subjects were equally divided into 2 groups: group F (30 eyes of 20 patients) underwent femtosecond laser-assisted LASIK surgery and group M (30 eyes of 18 patients) underwent microkeratome assisted LASIK surgery for the treatment of myopia.

The two groups were chosen from the refractive clinic of Benha University Hospital and were planned to undergo the LASIK procedure.

Patients were enrolled in the study according to the following inclusion criteria: age range between 18 years and 35 years, having moderate degree of myopia from (3.0) to (-6.0) diopters (D) and all patients fulfilled all the criteria for safe and successful LASIK procedure. While the exclusion criteria were: Preoperative PVD (partial or total) detected clinically or by optical coherence tomography, evidence of glaucomatous optic nerve damage, cup-disc ratio $>0.4$, diabetes, steroid 
responders or other systemic diseases known to affect the eye were excluded, disc anomalies as tilted disc were also excluded, prolonged suction time due to uncooperative patients or failed suction during the procedure were excluded and patients who had previous ocular or refractive surgeries was be excluded, as well as patients who have peripapillary atrophy upon fundus examination.

All patients underwent a complete preoperative examination including: Uncorrected visual acuity (UCVA), best corrected visual acuity (BCVA), manifest and cycloplegic refraction, anterior segment assessment including: Slit lamp examination, applanation tonometry and pentacam, posterior segment assessment including: slit lamp biomicroscopy and indirect ophthalmoscopy to exclude the presence and any associated retinal pathology. Macular and the peripapillary RNFL thickness measurements and assessment of PVD using optical coherence tomography.

\subsection{Intra-operative assessment}

The eye was fixated by a suction ring using negative pressure that was gradually built. A corneal flap was created using Femtosecond laser in 30 eyes, while the remaining 30 eyes had a flap created by microkeratome. The time of suction applied to the eye from "Suction ON" to "Suction OFF" was documented in each group, also any intraoperative complication.

\subsection{Surgical procedure}

Eye preparation and Anaesthesia: An eyelid speculum was inserted in the operative eye, which had been anesthetized topically, and the fellow eye was covered. The cornea was marked to aid postoperative flap alignment. The patient was instructed to look at the fixation light. A suction ring was applied to the globe.

Flap creation: Femtosecond laser or the microkeratome were used to create a hinged corneal flap. The flap hinge may be superior, nasal, or oblique depending on the microkeratome used. Depending on total corneal thickness, the flap thickness was chosen between 90 and 110 microns.

Laser remodelling: After lifting the flap, ablations was performed using the MEL 90 Zeiss Excimer laser and/or Visumax femtosecond laser.

Repositioning of the flap: Following ablation, the flap was repositioned with irrigation of the interface bed. Once flap alignment is verified and the peripheral gutters are inspected and found to be minimal and symmetric, the flap was allowed sufficient time to adhere. The eyelid speculum is carefully removed without disturbing the flap. The eye then examined at a slit-lamp biomicroscope 5 to 30 minutes later to verify flap alignment. Postoperative assessment
The same preoperative examinations was repeated 1 week post-operative

\subsection{Optical Coherence Tomography (OCT)}

Assessment of PVD and measurements of the macular and peripapillary retinal nerve fibre layer was measured using Topcon 3D OCT-2000 Series of Spectral Domain.

\section{Statistical Analysis}

Data were collected, revised, coded and entered to the Statistical Package for Social Science (IBM SPSS) version 23. The quantitative data were presented as mean, standard deviations and ranges when their distribution found parametric and median with interquartile range (IQR) when their distribution found non parametric. Also qualitative variables were presented as number and percentages. The comparison between groups with qualitative data were done by using Chisquare test and Fisher exact test instead of the Chisquare only when the expected count in any cell found less than 5. The comparison between two groups with quantitative data and parametric distribution were done by using Independent t-test. The comparison between two groups with quantitative data and parametric distribution were done by using Paired t-test. The confidence interval was set to $95 \%$ and the margin of error accepted was set to $5 \%$.

\section{Results}

30 eyes of 20 patients (group F) underwent femtosecond laser-assisted LASIK and 30 eyes of 18 patients (group M) underwent microkeratome-assisted LASIK. There was no statistically significant difference between the 2 groups regarding age, sex and spherical equivalent. There was a statistically significant difference in the suction time between the 2 groups.

The average preoperative RNFL thickness was $(103.00 \pm 13.21 \mu \mathrm{m})$ in the FS group and $(93.59 \pm 8.61$ $\mu \mathrm{m})$ in the MMK group. No statistically significant difference was found between both groups with regards to these parameters.

The mean "Suction ON" to "Suction OFF" time was (22 \pm 1.2 seconds) in the MMK group compared to $(32.97 \pm 1.19$ seconds) in the FS group. The LASIK procedure was uneventful in all patients.

One week after surgery, PVD (partial or complete) was detected in 8 eyes $(26.7 \%)$ in group $\mathrm{F}$ and 1 eye $(3.3 \%)$ in group $M$. The remaining study subjects showed no OCT evidence of PVD, neither partial nor total. The demographic data of both groups and the incidence of postoperative PVD and their significance ( $\mathrm{P}$ value) are demonstrated in Table 1-3. 
Table (1) Shows demographic data of both groups and their related p values.

\begin{tabular}{|c|c|c|c|c|c|c|}
\hline & & $\begin{array}{c}\text { Group M } \\
\text { No. }=18\end{array}$ & $\begin{array}{l}\text { Group F } \\
\text { No. }=20\end{array}$ & Test value & P-value & Sig. \\
\hline Age & $\begin{array}{l}\text { Mean } \pm \text { SD } \\
\text { Ranoe }\end{array}$ & $\begin{array}{c}26.11 \pm 4.48 \\
21-35\end{array}$ & $\begin{array}{c}28.20 \pm 3.98 \\
21-35\end{array}$ & $-1.521 \bullet$ & 0.137 & NS \\
\hline Sex & $\begin{array}{l}\text { Female } \\
\text { Male }\end{array}$ & $\begin{array}{c}10(55.6 \%) \\
8(44.4 \%)\end{array}$ & $\begin{array}{c}8(40.0 \%) \\
12(60.0 \%)\end{array}$ & $0.920^{*}$ & 0.338 & NS \\
\hline
\end{tabular}

Table (2) Shows the mean spherical equivalent and suction time of both groups.

\begin{tabular}{|c|c|c|c|c|c|c|}
\hline & & $\begin{array}{c}\text { Group M } \\
\text { No. }=\mathbf{3 0}\end{array}$ & $\begin{array}{l}\text { Group F } \\
\text { No. }=\mathbf{3 0} \\
\end{array}$ & Test value & P-value & Sig. \\
\hline Spherical equivalent & $\begin{array}{l}\text { Mean } \pm \text { SD } \\
\text { Range }\end{array}$ & $\begin{array}{c}-4.43 \pm 0.85 \\
-6--3\end{array}$ & $\begin{array}{c}-4.60 \pm 0.86 \\
-6--3.25\end{array}$ & $0.793 \bullet$ & 0.431 & NS \\
\hline Suction time & $\begin{array}{l}\text { Mean } \pm \text { SD } \\
\text { Range }\end{array}$ & $\begin{array}{c}20.03 \pm 1.22 \\
18-22\end{array}$ & $\begin{array}{c}32.97 \pm 1.19 \\
31-35\end{array}$ & $-41.639 \bullet$ & 0.000 & HS \\
\hline
\end{tabular}

P-value $>0.05$ : Non significant; P-value $<0.05$ : Significant; P-value $<0.01$ : Highly significant $\bullet$ : Independent t-test

Table (3) Shows the macular thickness, RNFL thickness and the incidence of PVD in group M pre and post-operative.

\begin{tabular}{|c|c|c|c|c|c|c|}
\hline & & \multicolumn{2}{|c|}{ Group M } & \multirow{2}{*}{ Test value } & \multirow{2}{*}{ P-value } & \multirow{2}{*}{ Sig. } \\
\hline & & Pre-operative & Post-operative & & & \\
\hline Macular thickness & $\begin{array}{l}\text { Mean } \pm \text { SD } \\
\text { Range }\end{array}$ & $\begin{array}{c}221.67 \pm 19.93 \\
187-257\end{array}$ & $\begin{array}{c}221.30 \pm 21.17 \\
182-257\end{array}$ & $0.455 \bullet$ & 0.652 & NS \\
\hline RNFL thickness & $\begin{array}{l}\text { Mean } \pm \text { SD } \\
\text { Range }\end{array}$ & $\begin{array}{c}93.59 \pm 8.61 \\
77.41-110\end{array}$ & $\begin{array}{c}92.83 \pm 10.27 \\
71.33-112\end{array}$ & $1.317 \bullet$ & 0.198 & NS \\
\hline PVD & $\begin{array}{l}\text { No } \\
\text { Yes }\end{array}$ & $\begin{array}{c}30(100.0 \%) \\
0(0.0 \%)\end{array}$ & $\begin{array}{c}29(96.7 \%) \\
1(3.3 \%)\end{array}$ & $1.017^{*}$ & 0.313 & NS \\
\hline
\end{tabular}

(P-value > 0.05: Non significant; P-value < 0.05: Significant; P-value < 0.01: Highly significant *: Chi-square test; •: Independent t-test).

Table (4) Shows the macular thickness, RNFL thickness and the incidence of PVD in group F pre and post-operative.

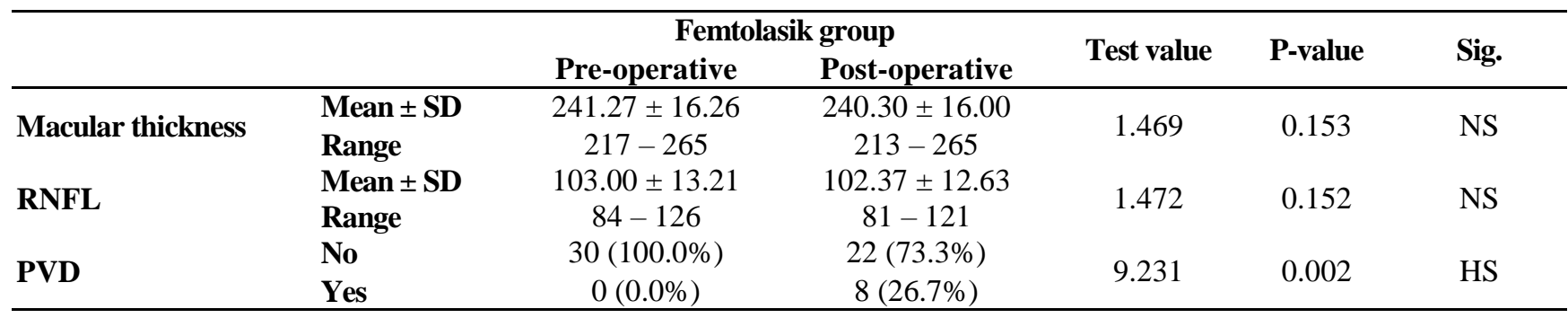

Table (5) Shows the difference in macular and RNFL thicknesses pre and post-operative in both groups

\begin{tabular}{lccccc}
\hline Difference & Lasik group & Femtolasik group & Test value & P-value & Sig. \\
\hline No. $=\mathbf{3 0}$ & $-0.37 \pm 4.41$ & $-0.97 \pm 3.61$ & $-0.577 \bullet$ & 0.566 & $\mathrm{NS}$ \\
RNFL thickness & $-0.76 \pm 3.16$ & $-0.63 \pm 2.36$ & $0.181 \bullet$ & 0.857 & NS \\
\hline
\end{tabular}

(P-value > 0.05: Non significant; P-value < 0.05: Significant; P-value < 0.01: Highly significant).

$\bullet$ : Independent t-test.

\section{Discussion}

In our study, a new generation of SD-OCT was used to evaluate the effect of applied suction during LASIK procedures on macular and RNFL thickness on
60 myopic eyes, whether the flap was created by microkeratome or Femtosecond laser.

LASIK-induced corneal alterations do not affect OCT imaging, making the latter more reliable in the 
evaluation of RNFL thickness in treated eyes than using other devices as Scanning Laser Polarimetry.

It was found in our study that the central macular thicknesses were not changed significantly in both groups when measured 1 week after surgery. Also, the RNFL thickness changes were found not be of significance and is unlikely to have clinical consequences.

A study conducted by Özülken and Đlhan on randomly selected eye of 114 consecutive eligible patients was analyzed. Inclusion criteria were myopia up to -6.00 diopters and astigmatism up to -2.00 diopters. As clinically indicated, 50 patients underwent LASEK and 64 underwent FS-LASIK. The RNFL thickness was determined with a spectral-domain optical coherence tomography device preoperatively and 3 months postoperatively. In conclusion, there was no change in GCT, NFT, and CMT measured by the SD-OCT in the early period after femtosecond LASIK surgery and this goes in accordance with our study. [5]

Another study conducted by El-Mahdy et al. (2020) to assess structural and functional changes of macular and NFL using spectral domain optical coherence tomography (SD-OCT) following LASIK surgery using Moria microkeratome. They found that there was no statistically significant correlation between the effect of suction by microkeratome during LASIK surgery and its efficacy on macular and retinal nerve fiber layer. [6]

In accordance with our study, Hosny et al. (2013) used SD-OCT to evaluate the effect of applied suction during LASIK procedures on RNFL thickness in 40 myopic eyes, whether the flap was created by microkeratome or FS laser. The transient rise of IOP during suction was found to have no significant effect on RNFL thickness in both group. [7]

Gürses-Özden et al. (2000) as well as Tsai and Lin (2000) reported that RNFL thickness may decrease after uncomplicated LASIK procedures when measured by conventional scanning laser polarimetry (SLP) with a fixed corneal compensator. [8], [9] Yet in 2001, Gürses-Özden et al. (2001) came to the conclusion that LASIK does not affect the RNFL thickness, as measured by OCT, SLP, and scanning laser tomography. The authors found that the changes present in the SLP thickness measurements were due to corneal alterations. Zangwill et al. (2005) confirmed these previous findings, and stated that the post-LASIK thinning of RNFL measured using SLP with a fixed corneal compensator can occur due to altered corneal birefringence, and may not actually be present. [10]

Regarding the incidence of PVD, in our study, 60 eyes of 38 patients were examined preoperatively by OCT to exclude existing preoperative PVD. We used OCT because it is known to be more useful in the evaluation of the vitreoretinal interface and more easily detects a flat and shallow posterior hyaloid detachment more than US.

Cases with double application of suction due to suction loss or inadequate centration in the first application were excluded. This could explain the relatively small sample size compared with other studies.

The mean "Suction ON" to "Suction OFF" time was $(32.97 \pm 1.19$ seconds) in group F compared to (22 \pm 1.2 seconds) in group $\mathrm{M}$. We calculated the suction time in group $\mathrm{F}$ from the moment vacuum was applied until vacuum was released (not only the duration of femtosecond laser application), and in group $M$ from the start of application of the suction ring until suction was switched off. This explains the significantly longer duration of suction application in the femtosecond laser group. One week after surgery, PVD (partial or complete) was detected in 8 eyes $(26.7 \%)$ in group $\mathrm{F}$ and 1 eye $(3.3 \%)$ in group $\mathrm{M}$.

A study similar to ours was conducted by Wang et al. (2013) comparing the incidence of PVD in microkeratome-assisted-LASIK and femtosecondassisted LASIK. [8] This study included 2 groups involving 80 eyes (40 cases in each group). One group underwent femtosecond laser-assisted (IntraLase FS150; Abbott Medical Optics, American) LASIK surgery, and the other group underwent microkeratomeassisted (Amadeus II, Ziemer, Switzerland) LASIK surgery. Bscan ultrasonography and optical coherence tomography were performed preoperatively and 1 week, 1,3 , and 6 months postoperatively to detect the presence of PVD. This study showed $27.5 \%$ incidence of postoperative PVD in the femtosecond laserassisted LASIK group and $20 \%$ incidence of PVD in the microkeratome-assisted LASIK group. Thus, there was no statistically significant difference between the 2 studied groups (x2 $=2.257, \mathrm{P}=0.133$ ).

The incidence of PVD after femtosecond laserassisted LASIK agreed with that found in the study done by Wang et al., whereas the incidence of PVD after microkeratome-assisted LASIK (20\%) strongly disagreed with that resulting from our study (3.3\%). However, it should be noted that cases with double application of suction due to suction loss or inadequate centration in the first application were excluded from the study as well as cases with preoperative partial PVD and this may explain the decreased incidence of PVD in our study.

A study conducted by Osman et al. found that the incidence of PVD 1 month after femtosecond laserassisted LASIK with the IntraLase FS-150 (85 \%) was higher than that after microkeratome-assisted LASIK with the Moria M2 (20\%). The mean suction time was $18.6 \pm 2$ seconds in group $M$ and $63.6 \pm 4$ seconds in group F. [4]

However in our study the mean suction time was $32.97 \pm 1.19$ seconds in the FS group. Another difference is that The VisuMax has a low-suction curved interface, and no suction ring is applied to the eye. Visumax generates suction on the cornea via a curved contact glass, in contrast to Intralase, which applies suction on the conjunctiva and sclera via a suction ring. This leads to less IOP elevation when using Visumax compared to IntraLase FS-150. [11] 
The above-mentioned facts could explain the lower incidence of PVD after femtosecond laser-assisted LASIK $(27.5 \%)$ found in our study compared with the incidence found in the study conducted by study conducted by Osman et al. [4]

\section{Conclusion}

Slight localized changes of macular thickness and reduction of the RNFL thickness were caused by LASIK using the two major forms of flap creation, namely a femtosecond laser or a microkeratome. So the surgery of LASIK is safe and efficient, but surgeons should choose effective and safe suction mode, shorten the suction time and exclude potential retinopathy and pre-existing glaucoma before surgery to improve the safety and efficacy of LASIK. Regarding the incidence of PVD, it was found that femtosecond laser-assisted LASIK using Visumax femtosecond laser had a higher incidence than that after microkeratome-assisted LASIK. This may be due to the longer duration of suction during femtosecond LASIK, although the suction pressure is lower during the femtosecond laser procedure. This could trigger screening of patients who have previously undergone LASIK surgery, especially femtosecond laser-assisted LASIK, for posterior segment complications, which would enable their early management.

\section{References}

[1] M.Moshirfar, P.Bennett, Y.Ronquillo, Laser. In Situ Keratomileusis. [Updated 2020 Jul 31]. In: StatPearls [Internet]. Treasure Island (FL): StatPearls Publishing,vol.10,pp.230-240,2020.

[2] H. Diekmann and D. Fischer, Glaucoma and optic nerve repair. Cell Tissue Res.vol.353(2),pp.327337; 2013.

[3] J.Zhang, YH.Zhou, Effect of suction on macular thickness and retinal nerve fiber layer thickness during LASIK used femtosecond laser and Moria M2 microkeratome. Int J Ophthalmol. Vol.8(4),pp.777-783,2015.
[4] MH.Osman, NM.Khalil, MS.El-Agha, Incidence of Posterior Vitreous Detachment after Femtosecond LASIK Compared With Microkeratome LASIK. Cornea.vol.36(9),pp.1036-1039,2017.

[5] K.Özülken and Ç.Đlhan,Evaluation of Retinal Ganglion Cell Layer Thickness in the Early Period after Femtosecond LASIK Surgery. Turkish Journal of Ophthalmology,vol.50(4),pp.211215,2020

[6] E.S.El-Mahdy, E.S.Younis and M.S.Ahmed, "Effect of suction using moria microkeratome on macular and retinal nerve fiber layer thickness during lasik using optical coherence tomography." Al-Azhar Medical Journal vol.49(4),pp.198-200, 2020.

[7] M. Hosny,R.M.Zaki, R.A.Ahmed, N. Khalil and H.M. Mostafa, Changes in retinal nerve fiber layer thickness following mechanical microkeratomeassisted versus femtosecond laser-assisted LASIK. Clin Ophthalmol vol.7,pp.1919-1922,2013.

[8] T.T. Wang, Y. Wang, and S.Z. Zhao, Comparison of posterior vitreous detachment after femtosecond laser and microkeratome-assisted lase in situ keratomileusis. Zhonghua Yan Ke Za Zhi,vol.49,pp.309-14,2013.

[9] Y.Y.Tsai, and J.M. Lin, Effect of laser-assisted in situ keratomileusis on the retinal nerve fiber layer. Retina vol.20,pp.342-5,2000.

[10] L.M. Zangwill, T. Abunto, C. Bowd, R. Angeles, D.J. Schanzlin, and R.N. Weinreb, Scanning laser polarimetry retinal nerve fiber layer thickness measurements after LASIK. Ophthalmology,vol.112(2),pp.200-207, 2005.

[11] C. Strohmaier, C. Runge, O. Seyeddain, M. Emesz, C. Nischler, A. Dexl, G. Grabner, and H.A. Reitsamer, Profiles of intraocular pressure in human donor eyes during femtosecond laser procedures--a comparative study. Invest Ophthalmol Vis Sci,vol.54(1),pp.522-8; 2013. 